\title{
Trends in the Prevalence of Dental Fluorosis in the United States: A Review
}

\author{
Susan M. Szpunar, MPH* \\ Brian A. Burt, BDS, MPH, PhD \\ Program in Dental Public Health \\ School of Public Health \\ The University of Michigan \\ Ann Arbor, MI 48109-2029
}

fluoride during the years of tooth calcification. Serious study of dental fluorosis began in the early part of the century with McKay's pioneering work on the causes and distribution of mottling, first referred to as Colorado Brown Stain (20-26). Later, Dean developed and subsequently modified the first fluorosis index and community fluorosis index (CFI) (14-19) and was responsible for much of the epidemiologic study of fluorosis that occurred over the next 20 years. The early history of the study of dental fluorosis, dental caries, and the dental fluorosis-dental caries relation have been well documented elsewhere $(20,21)$ and will not be repeated here.

\section{Methods of Comparison}

Studies by Dean et al. that are most suitable for comparison with current research include the study of 21 cities performed in the late 1930s and early 1940s $(27,28)$. While there are other studies that may be used for comparison, these are of particular interest, as they were performed in areas of the United States where the optimal water fluoride concentration was considered to be $1.0 \mathrm{ppm}$. The percentage distribution of children by fluorosis index score, as well as the CFI scores and percent prevalence figures for the studies mentioned above, are shown in Table 1 (27-29). The CFI is computed by first assigning each individual a single Fluorosis Index score, based on the worst condition found on two teeth in the mouth. The number of persons with each score (normal to severe) is multiplied by the weight Dean assigned to that category. These products are then summed over all categories and divided by the number of subjects, to give the weighted average known as the CFI score. The weights for the categories are as follows: normal, 0 ; questionable, 0.5 ; very mild, 1; mild, 2; moderate, 3; and severe, 4 (16). Also, percent prevalence figures are calculated by determining the percentage of individuals with scores of "very mild" and higher; the score of "questionable" is included in the "normal" category when computing these prevalence figures.

\section{Recent Data}

After the considerable research on dental caries and dental fluorosis that occurred during the 1930 to mid1950s period, little epidemiologic research on the occur- 
TABLE 1

Percent Distribution of Children by Fluorosis Index Score, the CFI Score, and Overall Percent Prevalence of Fluorosis, 21 Cities Studied by Dean et al. (27-29)

\begin{tabular}{|c|c|c|c|c|c|c|c|c|c|c|}
\hline \multirow[b]{2}{*}{ City } & \multirow[b]{2}{*}{ ppm F } & \multirow[b]{2}{*}{$N$} & \multicolumn{6}{|c|}{ Fluorosis Index Category } & \multirow[b]{2}{*}{ CFI } & \multirow[b]{2}{*}{$\begin{array}{c}\% \\
\text { Prev. }\end{array}$} \\
\hline & & & Normal & $\begin{array}{l}\text { Quest- } \\
\text { tionable }\end{array}$ & $\begin{array}{l}\text { Very } \\
\text { Mild }\end{array}$ & Mild & $\begin{array}{l}\text { Mod- } \\
\text { erate }\end{array}$ & Severe & & \\
\hline C. Springs, CO & 2.6 & 404 & 6.4 & 19.8 & 42.1 & 21.3 & 8.9 & 1.5 & $1.27^{*}$ & 73.8 \\
\hline Galesburg, IL & 1.9 & 273 & 25.3 & 27.1 & 40.3 & 6.2 & 1.1 & 0.0 & 0.69 & 48.0 \\
\hline Elmhurst, IL & 1.8 & 170 & 28.2 & 31.8 & 30.0 & 8.8 & 1.2 & 0.0 & 0.67 & 40.0 \\
\hline Joliet, IL & 1.3 & 447 & 40.5 & 34.2 & 22.2 & 3.2 & 0.0 & 0.0 & 0.46 & 25.3 \\
\hline Maywood, IL & 1.2 & 171 & 39.2 & 27.5 & 29.2 & 4.1 & 0.0 & 0.0 & 0.51 & 33.3 \\
\hline Aurora, IL & 1.2 & 633 & 53.2 & 31.8 & 13.9 & 1.1 & 0.0 & 0.0 & 0.32 & 15.0 \\
\hline E. Moline, IL & 1.2 & 152 & 36.8 & 31.6 & 29.6 & 2.0 & 0.0 & 0.0 & 0.49 & 32.0 \\
\hline Kewanee, IL & 0.9 & 123 & 52.8 & 35.0 & 10.6 & 1.6 & 0.0 & 0.0 & 0.31 & 12.2 \\
\hline Pueblo, CO & 0.6 & 614 & 72.3 & 21.2 & 6.2 & 0.3 & 0.0 & 0.0 & 0.17 & 6.5 \\
\hline Elgin, IL & 0.5 & 403 & 60.5 & 35.3 & 3.5 & 0.7 & 0.0 & 0.0 & 0.22 & 4.2 \\
\hline Marion, $\mathrm{OH}$ & 0.4 & 263 & 57.4 & 36.5 & 5.3 & 0.8 & 0.0 & 0.0 & 0.25 & 6.1 \\
\hline Lima, $\mathrm{OH}$ & 0.3 & 454 & 84.1 & 13.7 & 2.2 & 0.0 & 0.0 & 0.0 & $0.09^{*}$ & 2.2 \\
\hline Middletown, $\mathrm{OH}$ & 0.2 & 370 & 84.3 & 14.6 & 1.1 & 0.0 & 0.0 & 0.0 & $0.08^{*}$ & 1.1 \\
\hline Zanesville, $\mathrm{OH}$ & 0.2 & 459 & 85.4 & 13.1 & 1.5 & 0.0 & 0.0 & 0.0 & $0.08^{*}$ & 1.5 \\
\hline Quincy, IL & 0.1 & 330 & 93.0 & 6.7 & 0.3 & 0.0 & 0.0 & 0.0 & $0.04^{*}$ & 0.3 \\
\hline Elkhart, IN & 0.1 & 278 & 91.3 & 8.3 & 0.4 & 0.0 & 0.0 & 0.0 & $0.04^{*}$ & 0.4 \\
\hline Portsmouth, $\mathrm{OH}$ & 0.1 & 469 & 88.9 & 9.8 & 1.3 & 0.0 & 0.0 & 0.0 & $0.06^{*}$ & 1.3 \\
\hline Mi. City, IN & 0.1 & 236 & 97.5 & 2.5 & 0.0 & 0.0 & 0.0 & 0.0 & $0.02^{*}$ & 0.0 \\
\hline Evanston, IL & 0.0 & 256 & 91.8 & 6.6 & 1.6 & 0.0 & 0.0 & 0.0 & $0.5^{*}$ & 1.6 \\
\hline Oak Park, IL & 0.0 & 329 & 90.6 & 8.8 & 0.6 & 0.0 & 0.0 & 0.0 & $0.05^{*}$ & 0.6 \\
\hline Waukegan, IL & 0.0 & 423 & 97.9 & 1.9 & 0.2 & 0.0 & 0.0 & 0.0 & $0.1^{*}$ & 0.2 \\
\hline
\end{tabular}

*Computed by the author.

TABLE 2

Percent Distribution of Children by Fluorosis Index Score, the CFI Score, and Overall Percent Prevalence of Fluorosis, Seven Communities in Illinois and Four Communities in Iowa (30-31)

\begin{tabular}{|c|c|c|c|c|c|c|c|c|c|c|}
\hline \multirow[b]{2}{*}{ City } & \multirow{2}{*}{$\begin{array}{l}\text { Factor } \\
\text { of } \\
\text { Optimal }\end{array}$} & \multirow[b]{2}{*}{$N$} & \multicolumn{6}{|c|}{ Dean's Fluorosis Index Category } & \multirow[b]{2}{*}{ CFI } & \multirow[b]{2}{*}{$\begin{array}{c}\% \\
\text { Prev }\end{array}$} \\
\hline & & & Normal & $\begin{array}{l}\text { Quest- } \\
\text { tionable }\end{array}$ & $\begin{array}{l}\text { Very } \\
\text { Mild }\end{array}$ & Mild & $\begin{array}{l}\text { Mod- } \\
\text { erate }\end{array}$ & Severe & & \\
\hline \multicolumn{11}{|l|}{ Bushnell \& Table } \\
\hline Grove & 4.0 & 136 & 12.5 & 15.4 & 16.9 & 25.0 & 7.4 & 22.8 & 1.88 & 72.1 \\
\hline $\begin{array}{l}\text { Abingdon, Elm- } \\
\text { wood, \& Ipava }\end{array}$ & 3.0 & 192 & 22.9 & 26.0 & 15.1 & 19.8 & 7.8 & 8.3 & 1.25 & 51.0 \\
\hline Monmouth & 20 & 143 & 18.2 & 28.7 & 23.1 & 16.8 & 8.4 & 4.9 & 1.16 & 53.2 \\
\hline Kewanee & 1.0 & 336 & 56.0 & 29.5 & 7.4 & 4.8 & 1.8 & 0.6 & 0.39 & 14.6 \\
\hline $\begin{array}{l}\text { Belle Plaine, Durant, } \\
\text { Marengo, \& Miss- } \\
\text { ouri Valley, IA }\end{array}$ & $\leq 0.0$ & 316 & 93.0 & 4.1 & 1.9 & 1.0 & 0.0 & 0.0 & 0.06 & 2.9 \\
\hline
\end{tabular}

rence of dental fluorosis has been carried out, especially in areas with optimal or above-optimal levels of fluoride in water. Then, in 1980, Driscoll et al. (30) reassessed the relation between fluorosis and caries in seven rural Illinois communities' concentrations of fluoride in the water supply; the results are shown in Table 2. Table 2 also includes data collected by the same examiners from four low-fluoride rural communities in lowa (31). Comparing Tables 1 and 2, Driscoll et al.'s CFI score for
Kewanee was 0.39 , similar to the 0.31 computed decades earlier by Dean et al. during the 21-city study (28). There were, however, eight children with unexplained "moderate" or "severe" fluorosis in Kewanee (30). In the negligible fluoride areas, only 2.9 percent of the children showed definite signs of fluorosis; the CFI value for these areas was 0.06 (Table 2).

The prevalence and severity of mottled enamel in 16 Texas communities from a recent study was compared 
TABLE 3

Percent Distribution of Children by Fluorosis Index Score, the CFI Score, and Overall Percent Prevalence of Fluorosis, 16 Communities in Texas (32)

\begin{tabular}{|c|c|c|c|c|c|c|c|c|c|c|}
\hline \multirow[b]{2}{*}{ City } & \multirow{2}{*}{$\begin{array}{c}\text { Factor } \\
\text { of } \\
\text { Optimal }\end{array}$} & \multirow[b]{2}{*}{$N$} & \multicolumn{6}{|c|}{ Dean's Fluorosis Index Category } & \multirow[b]{2}{*}{$\mathrm{CFI}$} & \multirow[b]{2}{*}{$\begin{array}{c}\% \\
\text { Prev. }\end{array}$} \\
\hline & & & Normal & $\begin{array}{l}\text { Quest- } \\
\text { tionable }\end{array}$ & $\begin{array}{l}\text { Very } \\
\text { Mild }\end{array}$ & Mild & $\begin{array}{l}\text { Mod- } \\
\text { erate }\end{array}$ & Severe & & \\
\hline Taylor & 4.3 & 190 & 0.5 & 4.7 & 32.6 & 30.5 & 31.1 & 0.5 & 1.91 & 94.7 \\
\hline Gatesville & 3.1 & 113 & 12.4 & 10.6 & 44.2 & 28.3 & 4.4 & 0.0 & 1.19 & 76.9 \\
\hline Abernathy & 2.9 & 67 & 4.5 & 1.5 & 19.4 & 41.8 & 32.8 & 0.0 & 2.02 & 94.0 \\
\hline Perryton & 2.7 & 90 & 8.9 & 8.9 & 42.2 & 33.3 & 6.7 & 0.0 & 1.33 & 82.2 \\
\hline Monahans & 2.7 & 170 & 20.0 & 4.1 & 32.4 & 30.0 & 13.5 & 0.0 & 1.35 & 75.9 \\
\hline Hillsboro & 2.7 & 200 & 2.5 & 7.0 & 52.0 & 34.5 & 4.0 & 0.0 & 1.37 & 90.5 \\
\hline Ft. Stockton & 2.5 & 301 & 20.9 & 13.3 & 38.2 & 24.2 & 3.3 & 0.0 & 1.03 & 65.7 \\
\hline Littlefield & 2.3 & 109 & 17.4 & 4.6 & 37.6 & 25.7 & 14.7 & 0.0 & 1.35 & 78.0 \\
\hline Alpine & 2.3 & 23 & 21.7 & 4.3 & 21.7 & 39.1 & 13.0 & 0.0 & 1.41 & 73.8 \\
\hline Kerrville & 1.4 & 128 & 52.3 & 32.0 & 14.8 & 0.8 & 0.0 & 0.0 & 0.32 & 15.6 \\
\hline Angleton & 1.3 & 187 & 39.0 & 28.3 & 21.4 & 10.2 & 1.1 & 0.0 & 0.59 & 32.7 \\
\hline Alvin & 1.3 & 211 & 49.8 & 21.3 & 22.3 & 5.7 & 0.9 & 0.0 & 0.47 & 28.9 \\
\hline Kingsville & 1.0 & 361 & 39.6 & 21.1 & 36.6 & 2.5 & 0.3 & 0.0 & 0.53 & 39.4 \\
\hline San Antonio & 0.4 & 126 & 92.1 & 5.6 & 2.4 & 0.0 & 0.0 & 0.0 & 0.05 & 2.4 \\
\hline San Marcos & 0.3 & 223 & 81.2 & 10.3 & 8.5 & 0.0 & 0.0 & 0.0 & 0.14 & 8.5 \\
\hline N. Braunfels & 0.3 & 103 & 60.2 & 31.1 & 6.8 & 1.9 & 0.0 & 0.0 & 0.26 & 8.7 \\
\hline
\end{tabular}

TABLE 4

Percent Distribution of Children by Fluorosis Index Score and Overall Percent Prevalence of Fluorosis, Fluoridated and Nonfluoridated Areas of New York State (35)

\begin{tabular}{|c|c|c|c|c|c|c|}
\hline \multirow[b]{2}{*}{ F Status } & \multirow[b]{2}{*}{$\mathrm{N}$} & \multicolumn{4}{|c|}{ Fluorosis Index Category } & \multirow[b]{2}{*}{$\%$ Prev } \\
\hline & & Normal & $\begin{array}{l}\text { Very } \\
\text { Mild }\end{array}$ & Mild & Moderate & \\
\hline Fluoridated & 729 & 73.1 & 22.6 & 3.2 & 1.1 & 26.9 \\
\hline Nonfluoridated & 564 & 95.6 & 2.7 & 1.1 & 0.6 & 4.4 \\
\hline
\end{tabular}

by Segreto et al. (32) with the findings of Dean $(18,27,28)$ and Richards (33) (Table 3$)$. The study population consisted of continuous-resident children, aged nine to 12 and 14 to 18 years, who were scored for dental fluorosis using Dean's index. Segreto et al. reported a higher prevalence of fluorosis but lower severity. Extrinsic and intrinsic stains that could not be attributed to fluorosis, however, were placed in the "questionable" category, which might have artificially elevated the CFI scores.

Oldak and Leverett (34) reported that 22 percent of first and second grade children living in a nonfluoridated area of New York experienced dental fluorosis in the permanent teeth, but less than 1 percent had fluorosis in the primary teeth. Children who had received dietary fluoride supplements had significantly lower DMFS scores than children who did not receive supplements, but they were also more likely to have dental fluorosis.

In a further investigation of the prevalence of fluorosis in New York, Leverett (35) found that the prevalence of dental fluorosis was 3.5 times higher in non- fluoridated communities and two times higher in fluoridated communities than would be expected based on Dean's findings in 1942. Leverett modified Dean's index by combining scores from the "questionable" category with scores from the "normal" category when computing CFI scores; in addition, anterior teeth were not scored. These modifications would lead to more conservative estimates of the prevalence of fluorosis than Dean's traditionally computed CFI. The percent prevalence of fluorosis by fluorosis index category and the overall percent prevalence of fluorosis from Leverett's investigation are displayed in Table 4.

In Auckland, New Zealand, Cutress et al. found that diffuse enamel opacities occurred more frequently in fluoridated than nonfluoridated areas $(P<0.001)$, with a mouth prevalence of 19 percent in the fluoridated areas, but only 8 percent in the nonfluoridated areas (36). Noting the growing belief that the primary cariespreventive effects of fluoride may be topical, rather than systemic (37), the authors suggested that the ranges of optimal water fluoride values be reassessed and possibly decreased. In Denmark, Wenzel et al. (38) 
TABLE 5

Percent Distribution of Children by Fluorosis Index Score, the CFI Score, and Overall Percent Prevalence of Fluorosis, Aasenden and Peebles (39) and Hennon et al. (40)

\begin{tabular}{|c|c|c|c|c|c|c|c|c|c|}
\hline \multirow[b]{2}{*}{ Study Group } & \multirow[b]{2}{*}{$\mathrm{N}$} & \multicolumn{6}{|c|}{ Dean's Fluorosis Index Category } & \multirow[b]{2}{*}{ CFI } & \multirow[b]{2}{*}{$\begin{array}{c}\% \\
\text { Prev. }\end{array}$} \\
\hline & & Normal & $\begin{array}{l}\text { Quest- } \\
\text { tionable }\end{array}$ & $\begin{array}{l}\text { Very } \\
\text { Mild }\end{array}$ & Mild & $\begin{array}{l}\text { Mod- } \\
\text { erate }\end{array}$ & Severe & & \\
\hline \multicolumn{10}{|l|}{ Aasenden and } \\
\hline F supplement & 100 & 16.0 & 17.0 & 34.0 & 19.0 & 14.0 & 0.0 & 0.88 & 67.0 \\
\hline No supplement & 93 & 82.8 & 12.9 & 3.2 & 1.1 & 0.0 & 0.0 & 0.07 & 4.3 \\
\hline F water & 92 & 37.0 & 30.4 & 21.7 & 8.7 & 2.2 & 0.0 & 0.40 & 32.6 \\
\hline \multicolumn{10}{|l|}{ Hennon et al.: } \\
\hline $\begin{array}{r}\text { Supplement } \\
0.5 / 1.0 \mathrm{mg}\end{array}$ & 32 & 65.6 & 25.0 & 6.3 & 3.1 & 0.0 & 0.0 & 0.25 & 9.4 \\
\hline $\begin{array}{l}\text { Supplement } \\
0.5 \mathrm{mg} .\end{array}$ & 32 & 65.6 & 31.3 & 3.1 & 0.0 & 0.0 & 0.0 & 0.18 & 3.1 \\
\hline Control & 30 & 93.3 & 6.7 & 0.0 & 0.0 & 0.0 & 0.0 & 0.03 & 0.0 \\
\hline
\end{tabular}

assessed the prevalence of fluorosis and localized enamel opacities in children from areas with less than $0.2,1.0$, and $2.4 \mathrm{ppm}$ fluoride in the community water supply. CFI scores for the three areas were $0.02,0.56$, and 1.33 , respectively.

Aasenden and Peebles (39) attempted to determine the effects of fluoride supplementation from birth on the primary and permanent teeth of white children, using the original fluoride dosage schedule recommended by the American Academy of Pediatrics (AAP). Three study groups were formulated: a group of children in a nonfluoridated area who received a $0.5 \mathrm{mg}$ F supplement per day from birth to age three and then a $1.0 \mathrm{mg}$ F supplement thereafter, a control group from the same community, and a control group from an optimally fluoridated community. The percent prevalence of fluorosis by Fluorosis Index score and the CFI values are listed in Table 5. Results from a similar study by Hennon et al. (40) also are listed in Table 5 . Hennon et al. used Dean's index; however, no attempt was made to differentiate between fluoride and nonfluoride opacities-all were counted as fluorosis.

The effect of chewable acidulated phosphate fluoride (APF) tablets on the occurrence of dental caries and dental fluorosis was assessed in North Carolina schoolchildren over a 55-month interval (41). The results of the study indicated that over all study groups, 17 percent of the subjects had "questionable" dental fluorosis, with 11 of those children in the control group. Approximately 18 percent of the children who received one tablet per day were diagnosed as having "questionable" fluorosis, and 20.8 percent of the children receiving two tablets per day had this diagnosis. Only four children exhibited definite dental fluorosis, and two of those children were in the control group. Because of lack of teacher cooperation, however, compliance with the two-tablet-per-day regimen was lower than in the one-tablet-per-day group. If the two tablet regimen had been adhered to more closely, more cases of definite dental fluorosis might have developed.

\section{Discussion}

When interpreting the results of the 21-day study and using them for comparison with more recent data, we felt it was important to understand the study conditions and flaws. Dean et al. selected the particular 21 cities because they possessed the "requisites for quantitative evaluation" previously described (42). The cities varied widely in population size and subjects were restricted to Caucasians. Children were relied upon to provide water history information. The percentage of continuous histories was unusually low in Evanston, Oak Park, and Maywood, Illinois, most likely because of families leaving town for the summer and movement in and out of Chicago. Although examiner standardization was reportedly done, measures of examiner agreement were not published routinely. Most importantly, examiners were not blind to city of residence, suggesting that they could have been influenced by their knowledge of the fluoride concentration of the city water supply, other examining experiences, "gut" feelings, and other unconscious assumption or hopes.

Other problems inherent in the comparison of current and historic data should be considered. First, even if the same index is used, examiners may be applying criteria differently. One can speculate whether the sense of esthetics during the harshness of the Depression was as refined as it is today, and whether any such distinctions unconsciously affect the way mild fluorosis is scored. One can never quantify or compensate for these subjective differences, which could result from the sense of esthetics prevailing at that time. When Dean's index was not used, such as in the study of Cutress et al., valid comparisons are even more difficult. From studies using different indices, the percent prevalence of fluorosis may be the only comparison. Even this comparison, however, may be questionable if prevalence is defined in different ways-for example, if the "questionable" category of Dean's index is added to the categories indicating definite dental fluorosis (very mild to severe) instead of being included with the "nor- 
mal" category. Dean estimated that "... from the continuous use of water containing $1.0 \mathrm{ppm} \mathrm{F}$. . the very mildest forms of mottled enamel may occur in about 10 percent of the group." (19) The validity of comparisons of today's data with Dean's "10 percent" rule of thumb has the same difficulties as do comparisons of fluorosis index and CFI scores.

Finally, in Dean's work, the examinations were "made in good light with the child seated facing a window," (43) whereas in recent studies artificial light was used. At lower levels of fluorosis severity, natural illumination may not be adequate to detect the mildest forms of dental fluorosis. There are other areas of dissimilarity between the studies in Table 1 and current reports, such as methods of subject recruitment and history taking. Although these types of differences do not totally invalidate comparison, it is probably true that any change detected in the prevalence of fluorosis is at least partially the result of different examining conditions and not entirely a valid change in the occurrence of enamel defects.

\section{"Segreto et al. did find an increased prevalence of dental fluorosis when comparing their data to Dean's data for cities with similar fluoride concentra- tions, but the severity was less. This indicates an increase in the prevalence of the very mildest forms of dental fluorosis."}

Of the recent studies discussed above, the work of Driscoll et al. has the greatest potential for comparison with Dean's 21-city study because some of the same cities were studied and Dean's index was used. Driscoll et al. $(30,31)$ did not find an increased prevalence of dental fluorosis in any of the areas studied. The presence of eight children with moderate or severe fluorosis in the optimally fluoridated area, however, is an intriguing finding worthy of further study.

Segreto et al. (32) did find an increased prevalence of dental fluorosis when comparing their data to Dean's data for cities with similar fluoride concentrations, but the severity was less. This indicates an increase in the prevalence of the very mildest forms of dental fluorosis. If all of the hypoplasia in Cutress et al.'s (36) "diffuse opacity" category is assumed to be dental fluorosis, then the prevalence of mild forms of dental fluorosis in fluoridated parts of New Zealand is about 19 percent, higher than the "expected" 10 percent, as well as the percent prevalence in Kewanee and several suboptimally fluoridated areas listed in Table 1. Similarly, OIdak and Leverett's (34) finding of a prevalence of 22 percent in nonfluoridated areas of New York is much higher than the percent prevalence found in the suboptimally or optimally fluoridated areas listed in Table 1. In agreement with Segreto's findings, Leverett (35) also noted that although mean fluorosis indices in New York were similar to those found by Dean in areas with similar water fluoride concentrations, the prevalence of fluorosis in the recent study was higher than that found by Dean in comparable communities. The CFI score for the 1.0 ppm area in Denmark (38), 0.56, is higher than the CFI for Kewanee (0.9 ppm) and is similar to the CFI of Maywood (1.2 ppm).

In their fluoride supplement study, Aasenden and Peebles (39) used Moller's modified version of Dean's index, and the teeth were dried prior to examination. The study also was not blind. One examiner scored all the children, but no measures of intraexaminer reliability were given. Despite the differences, the prevalence of fluorosis in the group receiving fluoridated water, 32.6 percent, is considerably higher than the 10 percent prevalence suggested by Dean to occur in optimally fluoridated areas.

Hennon et al.'s (40) results do not agree with Aasenden and Peebles (39), even though Hennon et al. scored all opacities as dental fluorosis. Aasenden and Peebles reported a community fluorosis index score of 0.88 in the $0.5 / 1.0 \mathrm{mg} / \mathrm{per}$ day fluoride supplement group, whereas Hennon et al. reported an index score of 0.25 for the group receiving the same dose. Possible explanations for this large difference include use of Dean's index (Hennon et al.) versus Moller's modified version, drying of the teeth by Aasenden and Peebles, different compliance rates with the regimen, differential exposure to other sources of fluoride, different interpretations of criteria by examiners, other sources of bias, and chance.

Thus, to the extent that these comparisons of recent research with historic data are valid, there appears to be a slight trend toward more fluorosis today than would be expected based upon findings in the late 1930s and the early 1940s. If indeed this trend is occurring, the most obvious explanation is an increase in the availability and simultaneous consumption of fluoride in many forms by the children in developed countries today. Prior to 1940, the main sources of fluoride exposure for most individuals were probably water and food. Since that time, however, the introduction of topical fluorides $(44,45)$, dietary fluoride supplements, and fluoridated dentifrices and mouthrinses has led to an increase in the number of potential sources of fluoride available. One result of this increased availability and use of fluoride may be an increased environmental uptake of elemental fluoride, which could result in an increase in the concentration of fluoride found in foods and water supplies over time. Leverett (46) suggests that " . . . we are approaching a critical mass of fluoride in the environment which is eliminating dental caries as a public health problem in the United States. . . ."

With the suggestions of Leverett (46) and Cutress (36) in mind, a brief look at modern sources of fluoride is in order. Fluids other than tap water that may contribute fluoride to the daily intake include bottled water (47), fruit juices $(48,49)$, carbonated soft drinks processed in fluoridated areas $(50,51)$, and ready-to-feed infant formulas $(48,49)$. Tea, known to be rich in fluoride, has 
been stated to contribute up to $2.7 \mathrm{mg}$ fluoride per day to the diet of child and adult tea drinkers (52-54). Powdered beverages that are reconstituted with water are also a source of fluoride ingestion in fluoridated areas.

McClure (55), in his 1947 review, observed that a few specific dietary items were high in fluoride, particularly fish, tea, and leafy greens. Newer, more sensitive methods of fluoride analysis may now permit more critical analyses of food fluoride values than was possible in McClure's time. Several studies of the fluoride content of specific food items and diets for adults (5658 ) and children $(48,49,59-62)$ have been carried out, but it is difficult to tell from these studies whether food fluoride values have increased, because of the differences in analytic methods used.

In 1967-68, San Filippo and Battistone (63) analyzed the fluoride content of four different diets from a "market basket" program in Baltimore, Maryland (1.0 ppm). The data indicated an average daily fluoride intake of $2.19 \mathrm{mg}$ (63). More recently, Singer et al. (64) estimated the average daily fluoride intake from 24 FDA "market basket" food collections made from 1975 to 1982 in different regions of the US. They found that $15-$ to 19 year-old males living in fluoridated areas $(<0.7 \mathrm{ppm})$ had an average daily fluoride intake of $1.85 \mathrm{mg}$ per day when the diet provided an estimated caloric intake of 2,800 calories. In nonfluoridated areas $(<0.3 \mathrm{ppm})$, the average daily fluoride intake was $0.86 \mathrm{mg}(64)$. Comparisons of the more recent data to San Filippo and Battistone's results are difficult because San Filippo and Battistone did not report the caloric value of the diets. If the caloric value of the diets that they analyzed in 1967-68 was around 2,800 calories, then the data suggest that the fluoride levels of foods have not changed appreciably over time.

\section{"... there appears to be a slight trend toward more fluorosis today than would be expected based upon findings in the late 1930s and the early 1940s."}

Researchers have attempted to assess the impact of the ingestion of fluoride from multiple sources on the prevalence of dental fluorosis. For example, recent studies have explored the relation of breast- and formula-feeding to the occurrence of dental fluorosis. Ericsson and Ribelius (65) found that formula-fed children had a tendency to more pronounced fluorosis than breast-fed children; however, there were no statistically significant differences between children breast-fed exclusively and those children who were formula-fed for at least nine months. In Sweden, Forsman and Ericsson (66) did not detect fluorosis in breast- or formula-fed children even though water-diluted dry milk formulas may lead to relatively high fluoride ingestion compared to breast-feeding.

Forsman (67), in a study of dental fluorosis and infant feeding patterns in Sweden, found that dental fluorosis was correlated with different infant diets and the calculated supply of fluoride per kilogram of body weight. At about $0.1 \mathrm{mg} \mathrm{F} / \mathrm{kg}$, a dose that could be reached in a variety of ways, extremely mild dental fluorosis began to occur. Based upon the analysis of 44 market basket food collections, Ophaug et al. (61) determined that the average dietary fluoride intake of infants and toddlers did not exceed $0.08 \mathrm{mg} / \mathrm{kg}$. They calculated that the additional ingestion of fluoridated dentifrices or waterdiluted milk formulas, however, could result in ingestion levels above $0.1 \mathrm{mg} / \mathrm{kg}$. In a study of dental fluorosis and infant feeding patterns, Walton and Messer (68) found that 35 percent of the mixed dentitions had "mild" or "very mild" dental fluorosis on the permanent teeth.

\section{"Prior to 1940, the main sources of fluoride exposure for most individuals were probably water and food. Since that time, however, the introduction of topical fluorides, dietary fluoride supplements, and fluoridated dentifrices and mouthrinses has led to an increase in the number of potential sources of fluoride available."}

Difficulties in the study of infant feeding patterns and early fluoride exposure include problems with recall and potential differences between mothers who choose to breast- or bottle-feed. There may be significant socioeconomic and educational differences between mothers who choose to breast-feed and those who do not. This may be linked with different amounts of health knowledge, preventive orientation, and subsequent health-related behaviors that occur when children are growing up.

The amount of fluoride ingested from the topical application of fluoride has been found to range from $1.27 \mathrm{mg}$ to $31.2 \mathrm{mg}$, depending on the type of tray system used, the amount applied, the age of the patient, and the type of evacuation used (69-72). Larsen et al. (73) found that neither the semiannual nor the quarterly application of fluoride resulted in an increased prevalence of dental fluorosis in Danish children residing in a $0.1 \mathrm{ppm}$ area.

Ericsson and Forsman (75) found that the amount of fluoride ingested from mouthrinsing by preschoolaged children could be quite large because of immature swallowing mechanisms. Dowell (76) investigated the use of toothpaste by three-year-old children in Bristol, England, and found that 100 percent of the children brushed at least once daily by age three, with children of regular dental attenders being more likely than children of irregular attenders to brush twice daily or more. Eight percent of the mothers reported that children sometimes ate the paste directly from the tube. Barnhart et al. (77) found that children consistently con- 
sumed more toothpaste than adults, even though the average amount of paste used per brushing did not vary with age. Using a wide variety of methods, other investigators have assessed the amount of fluoride ingested by children and adults from dentifrices. The results of these studies vary somewhat because of the different methods of analysis used, age of subjects, and amount of dentifrice put on the brush (75-81).

\section{"... when considering the multiple sources of fluoride now available and the possible increase in environmental levels of fluoride, an increase in the prevalence of the very mildest forms of dental fluorosis should be neither surprising nor disturbing."}

Few studies have been performed on the relation between dental fluorosis and fluoride ingested from toothpaste and other forms of topically applied fluoride. Houwink and Wagg (82) studied the effect of fluoride dentifrice usage during infancy on the prevalence of dental fluorosis and found no hypoplasias that could be attributed to fluoride. They did not report, however, how often the children used the paste, how much was used, or how much was ingested. The latent period between mineralization of the teeth and eruption, as well as the difficulty in measuring product use, complicate the determination of an effect of fluoride dentifrices on dental fluorosis.

To summarize, when considering the multiple sources of fluoride now available and the possible increase in environmental levels of fluoride, an increase in the prevalence of the very mildest forms of dental fluorosis should be neither surprising nor disturbing. Obviously, more research is required to verify this trend; additional data on the prevalence of dental fluorosis and fluoride consumption need to be collected and stored in accessible data bases. Researchers planning the collection of such data should choose methods and indices with an eye to future need for comparison. In future studies, if Dean's index is used, the public health importance of various degrees of dental fluorosis may need to be reassessed. What Dean considered to be objectionable may not be considered objectionable today-extremely mild dental fluorosis is often thought to be esthetically pleasing.

An increase in the mildest forms of dental fluorosis, while neither damaging nor disfiguring, suggests that fluoride consumption has increased. If these trends continue, then the fluorosis could become more severe. Leverett (46) and Cutress (36) have suggested that water fluoride concentration ranges be reassessed in light of the decline in dental caries and the suggested increase in dental fluorosis. However, the increase in dental fluorosis prevalence is not as clear-cut nor as widely accepted as the decline in dental caries. Thus it may be premature to suggest that the water fluoride concentration values that have served so well, and are backed by a body of empirical evidence, be reduced on the basis of a weak, but nevertheless apparent, trend of increase in the mildest forms of fluorosis.

Periodic monitoring of the prevalence of fluorosis in fluoridated and nonfluoridated areas will provide some information to verify the trend. Comparisons of older cohorts with younger cohorts may reveal if fluorosis is more severe in a particular generation. Horowitz et al. (83), in the seven Illinois communities surveyed in 1980, found that first molars and incisors in children aged eight to ten were affected with more fluorosis than were the same teeth in children aged 11 to 13 . This difference may result from abrasion or remineralization, as suggested by Aasenden and Peebles (84), or from increased fluoride consumption by younger children. To investigate these findings, more research will be required on the effects of fluoride on tooth development, such as basic cellular research studying the effects of fluoride on the ameloblast, and recent studies examining the stages of tooth development in which fluorosis may occur (85-87). In addition, more epidemiologic research will be needed to further clarify the trend and to identify the sources of fluoride or combination of sources most highly associated with dental fluorosis.

Future surveys of dental fluorosis should be designed to facilitate the comparison of new data with the historic information, without sacrificing the more objective and finite diagnosis of fluorosis that may be possible today, using recently developed indices. For example, researchers might use both Dean's index and one of the newer indices, such as the TSIF (83), to allow historical comparisons without losing the benefits of a newer, possibly more objective index. Although time consuming, the use of two indices would allow a smooth transition from the reliance on older techniques to newer methods, without losing the wealth of data generated from the older methods. The increased use of direct-entry data programs may offset some of the time lost when using two indices.

". . future epidemiologic studies
will help dentistry to decide what
changes should be made if a need to
reduce fluoride exposure becomes
evident."

In addition to providing a bank of baseline information, future epidemiologic studies will help dentistry to decide what changes should be made if a need to reduce fluoride exposure becomes evident. For example, instead of reducing water fluoride concentrations, it may be more reasonable to decrease the fluoride concentration in dentifrices. Because toothpaste is a profitgenerating consumer product, however, this policy approach may be difficult to put into practice. Some policy changes have occurred: Aasenden and Peebles' study 
indirectly resulted in a reduction of fluoride dosage in the AAP dietary fluoride supplement prescription recommendations (88).

This review highlights the need for the continued study and monitoring of dental fluorosis in fluoridated and nonfluoridated communities, given the multitude of fluoride sources available today.

\section{References}

1. National Caries Program. National Institute of Dental Research. The prevalence of dental caries in US children 1979-80. The National Dental Caries Prevalence Surver. NiH publication no 82 2245, Dec 1981

2. Hunter PBV. The prevalence of dental caries in 5-vear-old New Zealand children. New Zealand Dent I 1979,75:154-7.

3. Mitropoulos CM, Worthington HV. Statistical aspects of caries prevalence data over a 12-year period in English schoolchildren. I Dent Res 1981;60:1154

4. Kalsbeek $\mathrm{H}$. Evidence of decrease in prevalence of dental caries in the Netherlands: an evaluation of epidemiological caries surveys in 4-6 and 11-15-vear-old children, performed between 1965 and 1980. J Dent Res 1982 Nov;61:1321-6.

5. Koch G. Evidence for declining caries prevalence in Sweden. I Dent Res 1982 Nov, 61:1,340-5.

6. O'Mullane DM. The changing patterns of dental caries in Irish schoolchildren between 1961 and 1981. J Dent Res 1982 Nov;61:1317-20

7. Brown RH. Evidence of decrease in the prevalence of dental caries in New Zealand. J Dent Res 1982 Nov:61:1327-30.

8. Anderson RJ, Bradnuck G. Beal JF, James PMC. The reduction of dental caries prevalence in English schoolchildren. J Dent Res 1982 Nor;61:1311-6.

9. Fejerskow O, Antoft P, Gadegaard E. Decrease in carjes experience in Danish children and young adults in the 1970s. J Dent Res 1982 Nov;61:1305-10.

10. von der Fehr FR. Evidence of decreasing caries prevalence in Norway. J Dent Res 1982 Nov;61:1331-5

11. Dean HT. Distribution of mottled enamel in the United States. Pub Health Rep 1933;48:703-34.

12. Dean HT, McKay FS. Production of mottled enamel halted by a change in common water supply. Am I Pub Health 1939;29:590-3.

13. Dean HT, McKay FS, Elvove E. Mottled enamel survey of Bauxite, Ark., 10 vears after a change in common water supply. Pub Health Rep 1938;53:736-48

14. Dean HT. Classification of mottled enamel diagnosis. J Am Dent Assoc 1934 Aug; 1421-6.

15. Dean HT, Elvove E, Poston RF. Mottled enamel in South Dakota. Pub Health Rep 1939;54:212-28.

1h. Dean HT. The investigation of physiological effects by the epidemiological method. In: Moulton FR, ed. Fluorine and Dental Health. AAAS Publication, 1942, no 19, pp 23-32.

17. Dean HT, Dixon RM, Cohen C. Mottled enamel in Texas. Pub Health Rep 1935 Mar;50:424-42.

18. Dean HT. Epidemiological studies in the United States. In: Moulton FR, ed. Dental Caries and Fuorine. AAAS Publication no 19. 1942.

19. Dean HT. Chronic endemic dental fluorosis (mottled enamel). ] Am Med Assoc 1936;107:1269-72.

20. McClure FS. Water Fluoridation: the Search and Victory. Bethesda, MD: National Institute for Dental Research, 1970

21. McNeil DR. The Fight for Fluoridation. New York: Oxford University Press, 1957.

22. McKay FS. Mottled enamel: carly history and unique features. In: Moulton FR, ed. Fluorine and Dental Health. AAAS Publication, 1942, pp $1-5$

23. McKay FS, Black GV. An investigation of mottled teeth: an endemic developmental imperfection of the enamel of the teeth, heretofore unknown in the literature of dentistry. Dent Cosmos 1916 May; $58: 477-84$

24. McKay FS. Black GI. An investigation of mottled teeth: an endemic developmental imperfection of the enamel of the teeth, heretofore unknown in the literature of dentistry. Dent Cosmos
1916 Jun; $58: 627-44$.
25. McKay FS, Black GV. An investigation of mottled teeth: an endemic developmental imperfection of the enamel of the teeth, heretofore unknown in the literature of dentistry. Dent Cosmos 1916 Jul; $58: 781-92$.

26. McKay FS. Mottled enamel: the prevention of its further production through a change in the water supply at Oakley, Idaho. J Am Dent Assoc 1933 Jul;20:1137-49.

27. Dean HT, Arnold FA Jr, Elvove E. Domestic water and dental caries II. A study of 2,832 white children, aged $12-14$ years, of eight suburban Chicago communities, including Lactobacillus acidophilus studies of 1,761 children. Pub Health Rep 1941 Apr; $\overline{6} 6: 761-92$.

28. Dean HT, Arnold FA Jr, Elvove E. Domestic water and dental caries $\mathrm{V}$. Additional studies of the relation of fluoride domestic waters to dental caries experience in 4,425 white children, aged $12-14$ years, of 13 cities in 4 states. Pub Health Rep 1942;57:115579 .

29. Galagan DJ. Climate and controlled fluoridation. J Am Dent Assoc $1953 ; 47: 159-70$

30. Driscoll WS, Heifetz SB, Horowitz HS, Kingman A, Meyers RJ, Zimmerman ER. Prevalence of dental caries and dental fluorosis in areas with optimal and above-optimal water fluoride concentrations. I Am Dent Assoc 1983 Jul;107:42-7.

31. Driscoll WS, Heifetz SB, Horowitz HS, Kingman A, Meyers RJ, Zimmerman ER. Prevalence of dental caries and dental fluorosis in areas with negligible, optimal, and above-optimal fluoride concentrations in drinking water. J Am Dent Assoc 1986 Jul;113:2933

32. Segreto VA, Collins EM, Camann D, Smith CT. A current study of mottled enamel in Texas. J Am Dent Assoc 1984 Jan;108:56-9.

33. Richards LF, Westmoreland WW, Tashiro M, McKay CH, Morrison JT. Determining optimum fluoride levels for community water supplies in relation to temperature. J Am Dent Assoc 1967;74:389-97.

34. Oldak B, Leverett DH. Dental fluorosis in a nonfluoridated community [Abstract]. J Dent Res 1984;63:197.

35. Leverett DH. Prevalence of dental fluorosis in fluoridated and nonfluoridated communities-a preliminary investigation. J Public Heaith Dent 1986 Fall;46:184-7.

36. Cutress TW, Suckling GW, Pearce EIF, Ball ME. Defects of tooth enamel in children in fluoridated and nonfluoridated water areas of the Auckland Region. New Zealand Dent J 1985 Jan;81:12-19.

37. Fejerskov O, Thylstrup A, Larsen MJ. Rational use of fluorides in caries prevention. Acta Odontol Scand 1981;39:241-9.

38. Wenzel A, Thystrup A, et al. Dental fluorosis and localized enamel opacities in fluoride and nonfluoride Danish communities. Caries Res 1982:16:340-8

39. Aasenden R, Peebles TC. Effects of fluoride supplementation from birth on human deciduous and permanent teeth. Arch Oral Biol 1974;19:321-6.

40. Hennon DK, Stookey GK, Beiswanger BB. Fluoride-vitamin supplements: effects on dental caries and fluorosis when used in areas with suboptimum fluoride in the water supply. J An Dent Assoc 1977;95:965-71.

41. Driscoll WS, Heifetz SB, Korts DC, Meyers RH, Horowitz HS. Effect of acidulated phosphate-fluoride chewable tablets in schoolchildren: results after 55 months. J Am Dent Assoc 1977;94:537-43

42. Dean HT, Elvove E. Some epidemiological aspects of chronic endemic fluorosis. Am J Pub Health 1936;26:567-75

43. Dean HT, Elvove E. Studies on the minimal threshold of the dental sign of chronic endemic fluorosis (mottled enamel). Pub Health Rep 1935;59:1719-29.

44. Bibby B. Fluorine and dental caries. NY J Dent 1945 Mar;15:99103.

45. Knutson JW, Armstrong WD. Effect of topically applied NaF on dental experience. Pub Health Rep 1943;58:1701-15.

46. Leverett $\mathrm{DH}$. Fluorides and the changing prevalence of dental caries. Science $1982 \mathrm{Jul} ; 217: 26-30$.

47. MacFadyen EE, McNee SG, Weetman DA. Fluoride content of some bottled spring waters. Br Dent J 1982 Dec;153:423-4.

48. Wiatrowski E, Kramer L, Osis D, Spencer H. Dietary fluoride intake of infants. Pediatrics 1975;55:517-22.

49. Singer L, Ophaug R. Total fluoride intake of infants. Pediatrics 1979 Mar;63:460-6 
50. Shulz EM, Epstein JS, Forrester DJ. Fluoride content of popular carbonated beverages. J Prev Dent 1976;3:27-9.

51. Shannon IL. Fluoride in carbonated soft drinks. Tex Dent J 1977 Mar;95:6-9.

52. Duckworth SC, Duckworth R. The investigation of fluoride in tea. Br Dent J 1978;145:368-70.

53. Cook HA. Fluoride intake through tea in British children. Fluoride $1970 ; 3: 12-8$.

54. Smid JR, Kruger BJ. The fluoride content of some teas available in Australia. Australian Dent J 1985;30:25-8.

55. McClure FJ. Fluorine in foods, survey of recent data. Pub Health Rep 1949;64:1061-74.

56. Kramer L, Osis D, Wiatrowski E, Spencer H. Dietary fluoride in different areas of the US. Am J Clin Nutr 1974;27:590.

57. Ham MP, Smith DM. Fluorine balance studies on three women. J Nutr 1954 Jun;53:225-32.

58. Marier JR, Rose D. The fluoride content of some foods and beverages. J Food Science 1966;31:941-6.

59. Singer L, Ophaug RH. Fluoride content in foods and beverages. In: Wei SHY, ed. National symposium on dental nutrition. Proceedings of a symposium at the University of Iowa, Iowa City: The University of Iowa College of Dentistry, 1978, pp 47-62.

60. Stamm JW, Kuo HC. Fluoride concentration in prepared infant foods [Abstract]. J Dent Res 1977;56:629.

61. Ophaug RH, Singer L, Harland BF. Dietary fluoride intake of 6month and 2-year-old children in four dietary regions of the United States. Am J Clin Nutr 1985;42:70-7.

62. Dabeka RW, McKenzie AD, Conacher HBS, Kirkpatrick DC. Determination of fluoride in Canadian infant foods and calculation of fluoride intakes by infants. Can J Pub Health 1982;73:188-91.

63. San Fillipo FA, Battistone GC. The fluoride content of a representative diet of the young adult male. Clin Chim Actn 1971;31:453.

64. Singer L, Ophaug RH, Harland BF. Dietary fluoride intake of 1519-year-old male adults residing in the United States. J Dent Res 1985 Nov;64:1302-5.

65. Ericsson Y, Ribelius U. Wide variations of fluoride supply to infants and their effects. Caries Res 1971;5:78-88.

66. Forsman B, Ericsson Y. Breastfeeding, formula feeding and dental health in low-fluoride districts in Sweden. Community Dent Oral Epidemiol 1974;2:1-6.

67. Forsman B. Early supply of fluoride and enamel fluorosis. Scand J Dent Res 1977;85:22-30.

68. Walton JL, Messer LB. Dental caries and fluorosis in breast-fed and bottle-fed children. Caries Res 1981;15:124-37.

69. McCall DR, Watkins TR, Stephen KW, Collins WJN, Smalls MJ. Fluoride ingestion following APF gel application. Br Dent J 1983 Nov;155:333-6.

70. Ekstrand J, Koch G. Systemic fluoride absorption following fluoride gel application. J Dent Res 1980 Jun;59:1067.
71. Ekstrand J, Koch G, Lindgren LE, Petersson LG. Pharmacokinetics of fluoride gels in children and adults. Caries Res 1981;15:21320.

72. Le Compte EJ, Doyle TE. Oral fluoride retention following various topical application techniques in children. J Dent Res 1982;61:1397-400.

73. LeCompte EJ, Rubenstein LK. Oral fluoride retention with thixotropic and APF gels and foam-lined and unlined trays. J Dent Res 1984;63:69-70.

74. Larsen MJ, Kirkegard E, Fejerskov O, Poulsen S. Prevalence of dental fluorosis after fluoride-gel treatments in a low-fluoride area. J Dent Res 1985 Aug;64:1076-9.

75. Ericsson $Y$, Forsman B. Fluoride retained from mouthrinses and dentifrices in pre-school children. Caries Res 1969;5:290-5.

76. Dowell TB. The use of toothpaste in infancy. Br Dent ] 1981;150:247-9.

77. Barnhart WE, Hiller LK, Leonard GJ, Michaels SE. Dentifrice usage and ingestion among four age groups. J Dent Res 1974;53:1,317-22.

78. Naylor MN, Melville M, Wilson RF, Ingram GS, Wagg BJ. Ingestion of a dentifrice by young children: a pilot study using fecal marker [Abstract]. J Dent Res 1971;50:687.

79. Hargreaves JA, Ingram GS, Wagg BJ. A gravimetric study of the ingestion of toothpaste by children. Caries Res 1972;6:237-43.

80. Glass RL, Petersen JKL, Zuckerberg DA, Naylor MN. Fluoride ingestion resulting from the use of a monofluorophosphate dentifrice by children. Br Dent J 1975;138:423-6.

81. Hargreaves JA, Ingram GS, Wagg BJ. Excretion studies on the ingestion of a monofluorophosphate toothpaste by children. Caries Res 1970;4:256-68.

82. Houwink B, Wagg BJ. Effect of fluoride dentifrice usage during infancy upon enamel mottling of the permanent teeth. Caries Res 1979;13:231-7.

83. Horowitz HS, Driscoll WS, Meyers RJ, Heifetz SB, Kingman A. A new method for assessing the prevalence of dental fluorosis - the tooth surface index of fluorosis. J Am Dent Assoc 1984 Jul;109:3741.

84. Aasenden R, Peebles TC. Effects of fluoride supplementation from birth on dental caries and fluorosis in teenaged children. Arch Oral Biol 1978;23:111-5.

85. Larsen MJ, Richards A, Fejerskov O. Development of dental fluorosis according to age at start of fluoride administration. Caries Res 1985;19:519-27.

86. Richards A, Kragstrup J, Josephsen K, Fejerskov O. Dental fluorosis developed in post-secretory enamel. J Dent Res 1986 Dec;12:1,406-9.

87. Ishii T, Suckling G. The appearance of tooth enamel in children ingesting water with a high fluoride content for a limited period during early tooth development. J Dent Res 1986 Jul;65:974-7.

88. American Association of Pediatrics. Committee on Nutrition. Fluoride as a nutrient. Pediatrics 1972;49:456-60. 